\title{
Adi ve Kısmi Diferansiyel Denklemlerin Çözümlerinin Kollokasyon Yöntemiyle Bulunması
}

\author{
Collocation Method for Solution of Ordinary and Partial Differantial Equations
}

Birkan DURAK*1,a

${ }^{1}$ Ístanbul Üniversitesi-Cerrahpaşa, Teknik Bilimler Meslek Yüksek Okulu, Uçak Teknolojisi Programı, 34500, İstanbul

• Geliş tarihi / Received: $28.01 .2020 \quad$ • Düzeltilerek geliş tarihi / Received in revised form: 15.09.2020 • Kabul tarihi / Accepted: 25.09 .2020

\begin{abstract}
$\ddot{O} z$
Mühendislik problemleri adi ve kısmi diferansiyel denklemler şeklinde matematiksel olarak ifade edilirler. Bu denklemlerin analitik çözümlerinin mümkün olmadığı durumlarda yaklaşık çözümler bulunmaya çalışılır. Çalışmada iki sınır değer probleminin yaklaşık çözümü kollokasyon metoduyla bulunmuştur. İlk problem homojen olmayan sınır şartlarına sahiptir. Problemin çözümde tanımlanan iki taban fonksiyonundan yararlanılmıştır. Aynı problem homojen olmayan sınır şartlarının homojenleştirilmesinin ardından iki kollokasyon noktası alınarak tekrar çözülmüşșür. İkinci problem ise homojen olmayan sınır şartlarına sahip Laplace denklemidir. Her iki problemin analitik çözümleri ile kollokasyon metoduyla bulunan yaklaşık çözümleri karşılaştırılmıştır. Kollokasyon nokta sayısı arttıkça yaklaşık çözüm her iki problemde analitik çözüme yakınsamaktadır. Ayrıca çözümdeki katsayıları bulmak için oluşturulan sistemdeki denklem sayısının, kollokasyon nokta sayısıyla birlikte arttığı görülmüsşür.
\end{abstract}

Anahtar kelimeler: Diferansiyel Denklemler, Kollokasyon Yöntemi, Sayısal Çözüm

\begin{abstract}
Engineering problems are often expressed mathematically as ordinary and partial differential equations. When analytical solution is not possible two base functions defined in solution of the problem were used. In this study, approximate solutions of two boundary value problem were found by collocation method. The first problem is that the selected two base functions are solved using nonhomogeneous boundary conditions. The same problem was resolved by homogenizing the nonhomogeneous boundary condition and taking two collocation points. The second problem is the Laplace equation with some nonhomogeneous boundary conditions. The analytical solution and collocation solution of this equation were compared. In both problems, as the number of collocation points increases, approximate solution approaches analytical solution. In addition, it was found that the number of equations in the system created to find the coefficients in the solution increased with the number of sorting points.
\end{abstract}

Keywords: Differential Equations, Collocation Method, Numerical Solution

*a Birkan DURAK; birkand@istanbul.edu.tr, Tel: (0212) 86637 00, orcid.org/0000-0002-8196-5407 


\section{Giriş}

Mühendislik problemleri uygun sınır şartlarıyla verilmiş olan diferansiyel denklemlerle ifade edilirler. $\mathrm{Bu}$ diferansiyel denklemler için analitik çözüm bulmak çoğu zaman mevcut çözüm yöntemleriyle mümkün olmamaktadır. Bazı durumlarda ise bulunan çözüm ilgilenilen problem hakkında ayrıntılı bilgi verecek kadar basit bir yapıda olmayabilir. $\mathrm{Bu}$ durumda sayısal yöntemlerle bazı sonuçlara ulaşarak problem hakkında daha fazla bilgiye ulaşılmaya çalışılır.

Adi diferansiyel denklemlerin çözümünde kullanılan belirsiz parametreler yönteminde sinır değer probleminin yaklaşı bir çözümü bulunmaya çalışılır. $\mathrm{Bu}$ çözüme yaklaşım fonksiyonu adı verilir. Seçilen yaklaşım fonksiyonun sınır şartlarını veya diferansiyel denklemi sağlaması yöntemin esasını oluşturur. Yaklaşım fonksiyonun terim sayısının ve bu fonksiyonun tanım aralığının, problemin çözümüne en iyi yaklaşımı belirleyen önemli iki faktör olduğu belirtilmiştir (Üstün, 2013). Bu çalışmada yaklaşım fonksiyonun tanım aralığ daraldıkça daha iyi yaklaşım sağlanacağ belirtilmiştir. Kollokasyon yöntemi uygulanırken yaklaşım fonksiyonu olarak periyodik problemler için trigonometrik polinomlar, periyodik olmayan problemler için Legendre polinomları ve Chebyshev polinomları, yarı sonsuz aralıkta tanımlı problemler için Laguerre polinomları ve reel eksen üzerinde tanımlı problemler için Hermite polinomları alınabilir (Uzunboy, 2016).

Bazı problem tiplerinde ise kısmen sınır şartlarını veya kısmen de denklemi sağlayan yaklaşım fonksiyonları seçilir (Bakioğlu, 2011). Bu fonksiyonların sağlamadığı şartlar üzerine çeşitli kriterler konularak yaklaşık olarak sağlatılması gerekir ve ağırlıklı kalan yöntemi olarak adlandırılmasının nedeni diferansiyel denklemin kalanları üzerinde konulan şartların bir ağırlık fonksiyonuyla çarpılarak verilmesidir.

Kollokasyon yöntemi, ağırlıklı kalanlar yöntemlerinden birisidir. Belirlenmemiş parametrelerin sayısı kadar nokta göz önüne alınır. $\mathrm{Bu}$ noktalarda yaklaşım fonksiyonun diferansiyel denkleme yazılmasiyla elde edilen kalanın, sıfıra eşit olmasını sağlayacak şekilde parametreler ayarlanmaya çalış1lır. Bu yöntemde kalanın, sıfır olduğu noktalar arasında bulunan tüm noktalarda sıfırdan uzaklaşmadığ 1 kabul edilir (Crandall, 1968).
Kollokasyon yöntemi adi diferansiyel denklemler başta olmak üzere kısmi diferansiyel, integral, integro-diferansiyel denklemlerin çözümünde kullanılan bir yöntemdir. Chebyshev kollokasyon metodu, adi diferansiyel denklemlerin yaklaş1k çözümlerini bulmakta kullanılmıştır (Wright, 1964; Dolapç1, 2004). Kollokasyon yöntemi integro-diferansiyel bir denklemin yaklaşık çözümünü bulmakta kullanılmıştır (Durak, 2018).

Bu çalışmada ise kollokasyon yöntemi adi ve kısmi diferansiyel denklemlerin çözümüne uygulanmıştır. $\mathrm{Bu}$ yöntemle bulunan yaklaşık ve analitik çözümler grafik olarak karşılaştırılmıştır. Kollokasyon nokta sayısı artışının yaklaşık çözüme olan etkisi incelenmiştir.

\section{Materyal ve Metot}

L bir diferansiyel operatör olmak üzere bir diferansiyel denklem

$$
L u=f(x)
$$

şeklinde gösterilebilir. Denklemin yaklaşık çözümü

$\hat{u}=\sum_{i=1}^{n} C_{i} \varphi_{i}(x)$

olsun. Burada $\varphi_{i}(x)^{\prime}$ ler sınır şartlarını sağlayan taban fonksiyonlarıdır. Bu çözüm (1) denklemine yazılırsa

$$
R(x)=L \hat{u}-f(x) \neq 0
$$

olacaktır. $R(x)$ 'e kalan (residual) denir. (2) denklemindeki $c_{i}$ katsayıları (1) eşitliğini sağlayacak tarzda seçilirler. Kollokasyon yönteminde kalan, seçilmiş kollokasyon noktalarında sıfıra eşitlenir. Kollokasyon noktaları $x_{i}$ ile gösterilirse

$$
R\left(x_{i}\right)=\mathrm{L} \hat{u}\left(x_{i}\right)-f\left(x_{i}\right)=0 \quad i=1,2,3 \ldots, n
$$

olacaktır. (4) ile verilen denklem, bir denklem sisteminin kapalı gösterimidir. $\mathrm{Bu}$ sistem $\mathrm{n}$ adet cebirsel denklemden oluşur ve çözülerek $C_{i}$ katsayıları bulunur. Bu katsayılar (2) de yerine yazıldığında (1) ile verilen diferansiyel denklemin yaklaşık çözümüne ulaşılır. 


\subsection{Kollokasyon Yönteminin Adi Diferansiyel Denklemlere Uygulanmast}

Kollokasyon yöntemi, yukarıda bahsedilen işlem adımları göz önüne alınarak adi diferansiyel denklemlerin yaklaşı çözümlerini bulmada kullanılabilir. $\mathrm{Bu}$ amaçla yöntem, aşağıda sınır şartlarıyla verilen bir diferansiyel denkleme uygulanarak yaklaşık çözüm bulunmuştur.

$$
y^{\prime \prime}+y=0
$$

bu denklemin sınır şartları ise

$$
\begin{aligned}
& y(0)=1 \\
& y(1)=0
\end{aligned}
$$

olarak verilmiş olsun, denklemin analitik çözümü

$$
y(x)=\cos (x)-\cot (1) \sin (x)
$$

şeklindedir. Denklemin sınır şartlarını sağlayan iki çözüm $(1-x)$ ve $(1-x)^{2}$ olarak seçilirse. $C_{1}$ ve $C_{2}$ keyfi sabitler olmak üzere denklemin genel çözümü

$$
y(x)=C_{1}(1-x)+C_{2}(1-x)^{2}
$$

olacaktır. $C_{1}$ ve $C_{2}$ sabitlerini bulmak için (6) ile verilen homojen olmayan sınır şartı ve denklem (5) kullanılmalıdır.

$$
y(0)=1 \quad \Rightarrow \quad C_{1}+C_{2}=1
$$

$R(x)=y^{\prime \prime}+y=2 C_{2}+C_{1}(1-x)+C_{2}(1-x)^{2}=C_{1}(1-x)+C_{2}\left[2+(1-x)^{2}\right]$

(11) ile verilen kalanın, keyfi bir x değeri için sıfır olması sağlanırsa (5) ile verilmiş olan diferansiyel denklemin çözümüne ulaşılacaktır. Kollokasyon noktasi $x=1 / 3$ olarak alınırsa

$$
R(1 / 3)=0 \quad \Rightarrow \quad 6 C_{1}+22 C_{2}=0
$$

denklemi bulunacaktır. (10) ve (12) denklemlerinden aşağıda verilen denklem sistemine ulaşılır.

$$
\begin{aligned}
& C_{1}+C_{2}=1 \\
& 6 C_{1}+22 C_{2}=0
\end{aligned}
$$

(13) ün çözümünden $C_{1}=1.375$ ve $C_{2}=-0.375$ olarak hesaplanarak (9) da yerine yazılırsa diferansiyel denklemin yaklaşık çözümü

$$
y(x)=1.375(1-x)-0.375(1-x)^{2}
$$

şeklinde bulunmuş olur. Verilen diferansiyel denklemdeki ilk sınır şartı homojen hale getirilerek farklı bir çözüme ulaşılabilir. Bu durumda 2 kollokasyon noktası kullanılmalıdır. Diferansiyel denklemin genel çözümü

$$
y(x)=u(x)+(1-x)
$$

formunda olsun, bu çözüme (6) ve (7) ile verilen sınır şartları uygulanırsa

$$
\begin{aligned}
& y(0)=1 \quad \Rightarrow \quad u(0)+1=1 \\
& y(1)=0 \quad \Rightarrow \quad u(1)+0=0
\end{aligned}
$$

eşitliklerine ulaş1ır. (15) ve (16) göz önüne alınarak (5) ile verilen denklem

$$
\begin{aligned}
& u^{\prime \prime}+u+1-x=0 \\
& u(0)=0 \\
& u(1)=0
\end{aligned}
$$

haline gelir. (17) nin sınır şartlarını sağlayan iki çözüm $x(1-x)$ ve $x(1-x)^{2}$ dir. $C_{1}$ ve $C_{2}$ keyfi sabitler olmak üzere denklemin genel çözümü

$$
u(x)=C_{1} x(1-x)+C_{2} x(1-x)^{2}
$$

olmaktadır. Bu çözüm (17) de yerine yazılırsa kalan

$$
R(x)=u^{\prime \prime}+u+1-x=C_{1}\left[x-x^{2}-2\right]+C_{2}\left[x(1-x)^{2}+6 x-4\right]+1-x
$$

olacaktır. Bu kalanın keyfi $x_{1}$ ve $x_{2}$ değerleri için sıfir olması sağlanırsa (17) ile verilmiş olan diferansiyel denklemin çözümüne ulaşılacaktır. Kollokasyon noktaları $x_{1}=1 / 3$ ve $x_{2}=2 / 3$ olarak seçilirse

$$
\begin{aligned}
& -45 C_{1}-50 C_{2}=-18 \\
& -48 C_{1}+2 C_{2}=-9
\end{aligned}
$$


şeklindeki denklem sistemine ulaş1lır. $\mathrm{Bu}$ denklemlerden $C_{1}=0.1952$ ve $C_{2}=0.1843$ olarak bulunur. $\mathrm{Bu}$ değerler denklem (18) de yazılırsa denklem

$$
y(x)=0.1952 x(1-x)+0.1843 x(1-x)^{2}+(1-x)
$$

olarak bulunur.

\subsection{Kollokasyon Yönteminin Kısmi Diferansiyel Denklemlere Uygulanmast}

Kollokasyon yöntemi kısmi diferansiyel denklemlerin çözümlerine de uygulanabilir. Bunun için aşağıda verilen Laplace denklemi göz önüne alsın.

Bu problemin analitik çözümü

$$
\begin{aligned}
& \frac{\partial^{2} u}{\partial x^{2}}+\frac{\partial^{2} u}{\partial y^{2}}=0 \quad 0<x<1,0<y<1 \\
& u(x, 0)=0 \\
& u(x, 1)=0 \\
& u(0, y)=1 \\
& u(1, y)=y
\end{aligned}
$$

haline gelir. (21) denklemi (15) denklemine yazılarak (5) denklemi ile verilen diferansiyel denklemin yaklaşı çözümü

$$
u=\sum_{n=1}^{\infty}\left[-2\left[1-(-1)^{n}+(-1)^{n} e^{n \pi}\right] e^{n \pi x}-2 e^{n \pi}\left[-(-1)^{n}-e^{n \pi}+(-1)^{n} e^{n \pi}\right] e^{-n \pi x}\right] \frac{\sin (n \pi y)}{n \pi\left(e^{2 n \pi}-1\right)}
$$

şeklindedir. Denklemin sınır şartlarını sağlayan iki çözüm $y(1-y)$ ve $y^{2}(1-y)$ olsun. $a_{1}(x)$ ve $a_{2}(x)$ keyfi fonksiyonlar olmak üzere denklemin genel çözümü

$$
u(x, y)=a_{1}(x) y(1-y)+a_{2}(x) y^{2}(1-y)
$$

olacaktır. (25) deki çözüm (23) de yerine yazılırsa denklem

$$
\frac{\partial^{2} u}{\partial x^{2}}+\frac{\partial^{2} u}{\partial y^{2}}=a_{1}^{\prime \prime}(x)\left(y-y^{2}\right)+a_{2}^{\prime \prime}(x)\left(y^{2}-y^{3}\right)+a_{1}(x)(-2)+a_{2}(x)(2-6 y)
$$

haline gelecektir. $\mathrm{Bu}$ denklem keyfi olarak belirlenen $y_{1}$ ve $y_{2}$ kollokasyon noktalarında sifira eşitlenerek $a_{1}(x)$ ve $a_{2}(x)$ keyfi fonksiyonları bulanabilir. (26) ile verilen denklem $R(x)$ fonksiyonu olarak tanımlanırsa

$$
\begin{aligned}
& R\left(y_{1}\right)=0 \\
& R\left(y_{2}\right)=0
\end{aligned}
$$

şeklindeki eşitlikler geçerlidir. Kollokasyon noktaları $y_{1}=1 / 3$ ve $y_{2}=2 / 3$ olarak alınıp (27) deki denklemlere yazılırsa

$$
\begin{aligned}
& 6 a_{1}^{\prime \prime}(x)+2 a_{2}^{\prime \prime}(x)-54 a_{1}(x)=0 \\
& 6 a_{1}^{\prime \prime}(x)+4 a_{2}^{\prime \prime}(x)-54 a_{1}(x)-54 a_{2}(x)=0 \\
& a_{1}(x)=A_{1} e^{r_{1} x}+A_{2} e^{r_{2} x}+A_{3} e^{r_{3} x}+A_{4} e^{r_{4} x} \\
& a_{2}(x)=B_{1} e^{r_{1} x}+B_{2} e^{r_{2} x}+B_{3} e^{r_{3} x}+B_{4} e^{r_{4} x}
\end{aligned}
$$

denklemlerine ulaş11ır. $a_{1}(x)=A e^{r x}$ ve $a_{2}(x)=$ $B e^{r x}$ şeklinde alınan çözümler (28) de yazılır ve düzenlenirse

$$
\begin{aligned}
& A\left(6 r^{2}-54\right)+B\left(2 r^{2}\right)=0 \\
& A\left(6 r^{2}-54\right)+B\left(4 r^{2}-54\right)=0
\end{aligned}
$$

olacaktır. (29) daki denklem sisteminde $A, B \neq 0$ şeklinde çözümün varlığı için katsayılar matrisinin determinantı sifir olmalıdır. Buradan

$$
\left(6 r^{2}-54\right)\left(2 r^{2}-54\right)=0
$$

olacaktır. Böylece $r_{1}=3, r_{2}=-3, r_{3}=$ $3 \sqrt{3}, r_{4}=-3 \sqrt{3}$ şeklinde bulunan dört kök 
ifadesinde yazılarak $a_{1}(x)$ ve $a_{2}(x)$ keyfi fonksiyonları

$$
\begin{aligned}
& a_{1}(x)=A_{1} e^{3 x}+A_{2} e^{-3 x}+A_{3} e^{3 \sqrt{3} x}+A_{4} e^{-3 \sqrt{3} x} \\
& a_{2}(x)=B_{1} e^{3 x}+B_{2} e^{-3 x}+B_{3} e^{3 \sqrt{3} x}+B_{4} e^{-3 \sqrt{3} x}
\end{aligned}
$$

şeklinde bulunur. Burada sekiz bilinmeyen katsayı vardır. (29) daki ilk denklem göz önüne alınarak $B_{k}$ katsayıları $A_{k}$ katsayıları cinsinden yazılabilir. Böylece bilinmeyen katsayılar dörde düşecektir.

$$
B_{k}=\frac{54-6 r_{k}^{2}}{2 r_{k}^{2}} A_{k}
$$

Katsayıları bulmak için (25) deki çözüme

$$
\begin{aligned}
& u\left(0, \frac{1}{3}\right)=a_{1}(0)\left(\frac{1}{3}-\left(\frac{1}{3}\right)^{2}\right)+a_{2}(0)\left(\left(\frac{1}{3}\right)^{2}-\left(\frac{1}{3}\right)^{3}\right)=1 \\
& u\left(0, \frac{2}{3}\right)=a_{1}(0)\left(\frac{2}{3}-\left(\frac{2}{3}\right)^{2}\right)+a_{2}(0)\left(\left(\frac{2}{3}\right)^{2}-\left(\frac{2}{3}\right)^{3}\right)=1 \\
& u\left(1, \frac{1}{3}\right)=a_{1}(1)\left(\frac{1}{3}-\left(\frac{1}{3}\right)^{2}\right)+a_{2}(1)\left(\left(\frac{1}{3}\right)^{2}-\left(\frac{1}{3}\right)^{3}\right)=\frac{1}{3} \\
& u\left(1, \frac{2}{3}\right)=a_{1}(1)\left(\frac{2}{3}-\left(\frac{2}{3}\right)^{2}\right)+a_{2}(1)\left(\left(\frac{2}{3}\right)^{2}-\left(\frac{2}{3}\right)^{3}\right)=\frac{2}{3}
\end{aligned}
$$

haline gelir. (36) denklemindeki $a_{1}(0), a_{1}(1), a_{2}(0), a_{2}(1)$ ifadeleri

$$
\begin{aligned}
& a_{1}(0)=A_{1}+A_{2}+A_{3}+A_{4}=\sum_{k=1}^{4} A_{k} \\
& a_{2}(0)=B_{1}+B_{2}+B_{3}+B_{4}=\sum_{k=1}^{4} B_{k} \\
& a_{1}(1)=A_{1} e^{3}+A_{2} e^{-3}+A_{3} e^{3 \sqrt{3}}+A_{4} e^{-3 \sqrt{3}}=\sum_{k=1}^{4} A_{k} e^{r_{k}} \\
& a_{2}(1)=B_{1} e^{3}+B_{2} e^{-3}+B_{3} e^{3 \sqrt{3}}+B_{4} e^{-3 \sqrt{3}}=\sum_{k=1}^{4} B_{k} e^{r_{k}}
\end{aligned}
$$

olmaktadır. $\mathrm{Bu}$ denklemler ise (34) deki sinır şartlarının (35) de yazılmasıyla elde edilmiştir. (33) deki eşitlikten faydalanılarak (37) deki

$$
\begin{aligned}
& u\left(0, \frac{1}{3}\right)=\sum_{k=1}^{4}\left[\frac{2}{9}+\frac{2}{27}\left(\frac{54-6 r_{k}^{2}}{2 r_{k}^{2}}\right)\right] A_{k}=1 \\
& u\left(0, \frac{2}{3}\right)=\sum_{k=1}^{4}\left[\frac{2}{9}+\frac{4}{27}\left(\frac{54-6 r_{k}^{2}}{2 r_{k}^{2}}\right)\right] A_{k}=1 \\
& u\left(1, \frac{1}{3}\right)=\sum_{k=1}^{4}\left[\frac{2}{9}+\frac{2}{27}\left(\frac{54-6 r_{k}^{2}}{2 r_{k}^{2}}\right)\right] A_{k} e^{r_{k}}=\frac{1}{3} \\
& u\left(1, \frac{2}{3}\right)=\sum_{k=1}^{4}\left[\frac{2}{9}+\frac{4}{27}\left(\frac{54-6 r_{k}^{2}}{2 r_{k}^{2}}\right)\right] A_{k} e^{r_{k}}=\frac{2}{3}
\end{aligned}
$$

$x=0 \quad$ da $u=1$

$x=1$ de $u=y$

(34) ile verilen sınır şartları uygulanırsa

$$
\begin{aligned}
& u(0, y)=a_{1}(0)\left(y-y^{2}\right)+a_{2}(0)\left(y^{2}-y^{3}\right) \\
& u(1, y)=a_{1}(1)\left(y-y^{2}\right)+a_{2}(1)\left(y^{2}-y^{3}\right)
\end{aligned}
$$

denklemleri elde edilir. $\mathrm{Bu}$ denklemler seçilen $y_{1}=1 / 3$ ve $y_{2}=2 / 3$ kollokasyon noktaları için 
şeklindeki denklem sistemine ulaşılır. Gerekli düzenlemelerin ardından bu denklem sisteminin matris gösterimi

$$
\left[\begin{array}{cccc}
\frac{2}{r_{1}^{2}} & \frac{2}{r_{2}^{2}} & \frac{2}{r_{3}^{2}} & \frac{2}{r_{4}^{2}} \\
\frac{36-2 r_{1}^{2}}{9 r_{1}^{2}} & \frac{36-2 r_{2}^{2}}{9 r_{2}^{2}} & \frac{36-2 r_{3}^{2}}{9 r_{3}^{2}} & \frac{36-2 r_{4}^{2}}{9 r_{4}^{2}} \\
\frac{2}{r_{1}^{2}} e^{r_{1}} & \frac{2}{r_{2}^{2}} e^{r_{2}} & \frac{2}{r_{3}^{2}} e^{r_{3}} & \frac{2}{r_{4}^{2}} e^{r_{4}} \\
\frac{36-2 r_{1}^{2}}{9 r_{1}^{2}} e^{r_{1}} & \frac{36-2 r_{2}^{2}}{9 r_{2}^{2}} e^{r_{2}} & \frac{36-2 r_{1}^{2}}{9 r_{3}^{2}} e^{r_{3}} & \frac{36-2 r_{4}^{2}}{9 r_{4}^{2}} e^{r_{4}}
\end{array}\right]\left[\begin{array}{c}
A_{1} \\
A_{3} \\
A_{4}
\end{array}\right]=\left[\begin{array}{c}
1 \\
1 \\
0.33 \\
0.66
\end{array}\right]
$$

gibi olmaktadır. Buradan katsayılar

$$
\begin{array}{ll}
\mathrm{A}_{1}=0.1011 & \mathrm{~B}_{1}=0 \\
\mathrm{~A}_{2}=4.3989 & \mathrm{~B}_{2}=0 \\
\mathrm{~A}_{3}=-0.0124 & \mathrm{~B}_{3}=0.0249 \\
\mathrm{~A}_{4}=0.0124 & \mathrm{~B}_{4}=-0.0249
\end{array}
$$

olarak bulunur. $\mathrm{Bu}$ katsayılar (32) de yazilarak $a_{1}(x)$ ve $a_{2}(x)$ fonksiyonlar1

$$
\begin{aligned}
& a_{1}(x)=0.1011 e^{3 x}+4.3989 e^{-3 x}-0.0124 e^{3 \sqrt{3} x}+0.0124 e^{-3 \sqrt{3} x} \\
& a_{2}(x)=0.0249 e^{3 \sqrt{3} x}-0.0249 e^{-3 \sqrt{3} x}
\end{aligned}
$$

gibi bulunmuş olur. (41) de bulunan bu fonksiyonlar (25) de yerine yazılarsa aranan kollokasyon çözümü

$$
\begin{aligned}
u(x, y)= & {\left[0.1011 e^{3 x}+4.3989 e^{-3 x}-0.0124 e^{3 \sqrt{3} x}+0.0124 e^{-3 \sqrt{3} x}\right.} \\
& \left.+y\left(0.0249 e^{3 \sqrt{3} x}-0.0249 e^{-3 \sqrt{3} x}\right)\right]\left(y-y^{2}\right)
\end{aligned}
$$

olacaktır.

\section{Bulgular}

(5) denklemi ile verilen ve (6), (7) sınır şartlarına sahip olan adi diferansiyel denklemin yaklaşık çözümü denklem (14) deki gibidir. Bu problem verilen sınır şartları altında ve homojen olmayan sınır şartı homojenleştirilerek ayrı ayrı çözülmüştür. Problemin analitik çözümü ve iki yaklaşık çözümü Şekil 1 de grafik halinde verilmiştir.

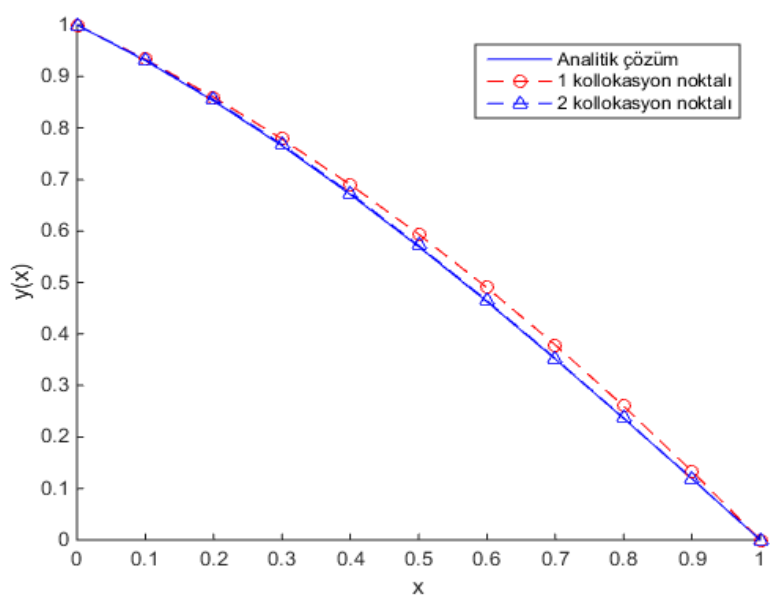

Şekil 1: Analitik ve kollokasyon çözümlerinin karşılaştırılması.

Tablo 1 de Analitik çözüm ve farklı kollokasyon nokta sayıları için bulunan yaklaşık çözümler verilmiştir. 
Tablo 1. Çözümün kollokasyon nokta sayısı ile değişimi

\begin{tabular}{cccccc}
\hline $\mathbf{x}$ & $\begin{array}{c}\text { Analitik } \\
\text { Çözüm }\end{array}$ & $\begin{array}{c}\text { 2 Kollokasyon } \\
\text { Noktası }\end{array}$ & $\begin{array}{c}\text { 4 Kollokasyon } \\
\text { Noktası }\end{array}$ & $\begin{array}{c}\text { 6 Kollokasyon } \\
\text { Noktası }\end{array}$ & $\begin{array}{c}\text { 8 Kollokasyon } \\
\text { Noktası }\end{array}$ \\
\hline & & & & & \\
\\
0 & 1.0000000 & 1.0000000 & 1.0000000 & 1.0000000 & 1.0000000 \\
0.1 & 0.9309018 & 0.9324963 & 0.9304970 & 0.9309001 & 0.9308941 \\
0.2 & 0.8525024 & 0.8548224 & 0.8517818 & 0.8524989 & 0.8524893 \\
0.3 & 0.7655851 & 0.7680841 & 0.7646369 & 0.7655798 & 0.7655690 \\
0.4 & 0.6710183 & 0.6733872 & 0.6699317 & 0.6710116 & 0.6710010 \\
0.5 & 0.5697469 & 0.5718375 & 0.5686125 & 0.5697396 & 0.5697294 \\
0.6 & 0.4627828 & 0.4645408 & 0.4616919 & 0.4627760 & 0.4627664 \\
0.7 & 0.3511947 & 0.3526029 & 0.3502388 & 0.3511893 & 0.3511812 \\
0.8 & 0.2360976 & 0.2371296 & 0.2353681 & 0.2360943 & 0.2360884 \\
0.9 & 0.1186415 & 0.1192267 & 0.1182300 & 0.1186402 & 0.1186375 \\
1.0 & 0.0000000 & 0.0000000 & 0.0000000 & 0.0000000 & 0.0000000 \\
\hline
\end{tabular}

Şekil 2 de homojenleştirilmiş sınır şartlarına sahip denklemin yaklaşı çözümünde alınan kollokasyon nokta sayısına göre Gerçek Mutlak Hatanın değerleri çeşitli x ler için verilmiştir.
Gerçek Mutlak Hata, gerçek çözüm ve sayısal çözüm arasındaki fark olarak bilinen gerçek hatanın mutlak değeridir (Karaboğa, 2012).

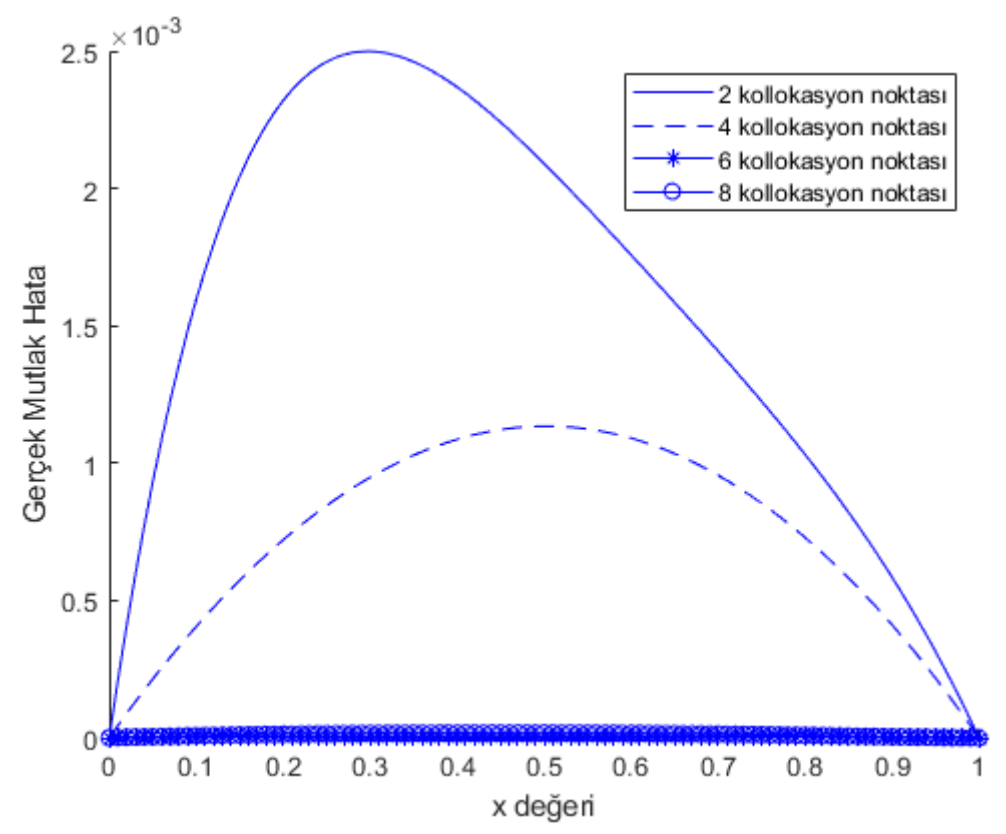

Şekil 2: Gerçek mutlak hatanın kollokasyon nokta sayısı ile değişimi

Denklem (23) ile verilen Laplace denkleminin analitik çözümü değişkenlerin ayrıştırılması yöntemi kullanılarak (24) deki gibi bulunmuştur. $\mathrm{Bu}$ problemin kollokasyon yöntemi ile bulunan yaklaşık çözümü denklem (42) deki gibidir. Bu çözümün grafiği bir yüzey gösterir. Şekil 3 de incelenen Laplace denklemi için analitik çözüm, kollokasyon çözümü ve Gerçek Mutlak Hata grafikleri verilmiştir.

\section{Tartışma ve Sonuçlar}

Birinci problem için kollokasyon nokta sayısı arttıkça sayısal çözümün analitik çözüme yaklaştığı görülmektedir. Analitik çözüme daha yakın sonuçlar bulabilmek için (9) ve (15) ile verilen genel çözümler

$$
\begin{aligned}
& y(x)=\sum_{n=1}^{N} C_{n}(1-x)^{n} \\
& y(x)=\sum_{n=1}^{N} C_{n} x(1-x)^{n}+1-x
\end{aligned}
$$

formunda alınarak farklı kollokasyon nokta sayıları için yaklaşık çözümler bulunmuştur.

Kollokasyon nokta sayısı arttırıldıkça Gerçek Mutlak Hatanın giderek küçüldüğü görülmektedir. Sayısal çözümler bulunurken kollokasyon nokta sayısı kadar denkleme sahip bir denklem sistemi oluşturularak çözülmektedir. 


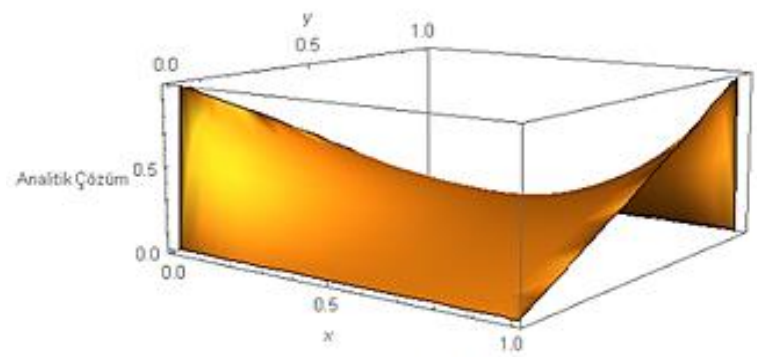

(a)

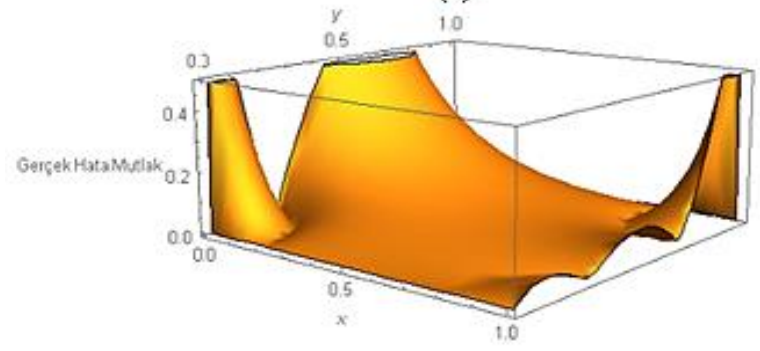

(c)

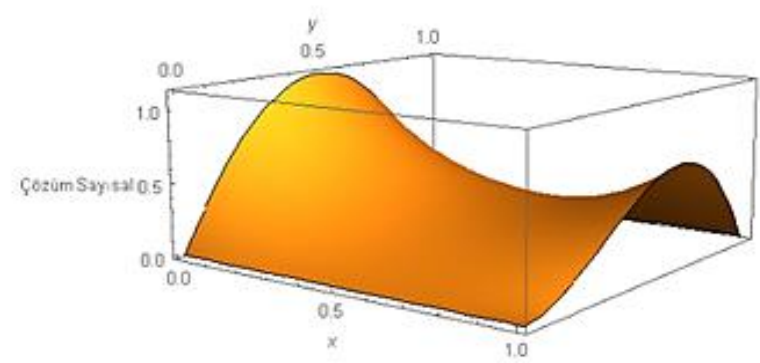

(b)

Şekil 3: Laplace denklemi için (a) Analitik çözüm, (b) Kollokasyon çözümü, (c) Gerçek mutlak hata

Şekil 2 incelendiğinde sekiz kollokasyon noktası alınarak yeterli hassaslıkta yaklaşık çözümlerin bulunabildiği görülmüştür.

İncelenen ikinci problemde (23) ile verilen k1smi diferansiyel denklemin analitik çözümü olan (24) denklemindeki terim sayısını arttırdıkça daha uygun sonuçlar bulunmaktadır. Yüksek sayıda terimin alınması halinde bulunan çözümün sınır şartlarını sağlayıp sağlamadığına dikkat edilmelidir. $\mathrm{Bu}$ diferansiyel denklemin kollokasyon çözümü (42) deki gibidir. Şekil 3 incelendiğinde Gerçek Mutlak Hatanın maksimum değerinin 0.6 dan küçük olduğu görülmektedir.

Probleme bağlı olarak hesaplamalarda kaç kollokasyon noktasının alınması gerektiği önemli bir sorundur. Hesaplama zamanın nokta sayısıyla doğru orantılı olduğu bulunmuştur. Daha karmaşık yapıdaki problemler çözülürken kaç kollokasyon noktasının alınacağını belirlemede Yaklaşık Mutlak Hatadan yararlanılabilir. Ardışık iki kollokasyon noktası için hesaplamalar yapılır. $\mathrm{Bu}$ iki hesaplama arasındaki farkın mutlak değeri belirli bir değerin altında ise çözüm yeterli hassaslıkta elde edilmiş olur.

\section{Teşekkür}

Yazar, makalenin inceleme ve değerlendirme aşamasında yapmış oldukları değerli katkılarından dolayı editör ve hakemlere teşekkür eder.

\section{Kaynaklar}

Bakioğlu, M., 2011. Sayısal Analiz: İstanbul, Birsen Yayınevi, 543s.
Crandall, S., 1968. Mühendislik Analizi Sayısal Hesap Metotlarına Genel Bakış, (çev: Şenol Utku, Ender ve Yazar Özden): İstanbul, İTÜ Kütüphanesi Elektronik Hesap Merkezi Yayınlar1, 552s.

Dolapçı, İ.T., Arslan, 2004. Chebyshev Collocation Method for Solving Linear Differantial Equations. Mathematical \& Computational Applications, 9(1), 107-115.

Durak, B., 2018. Kabuk Yapılarda Akışkan-Elastik Cisim Etkileşiminin Teorik İncelenmesi. Doktora Tezi, İstanbul Üniversitesi, İstanbul, $96 s$.

Karaboğa, N., 2012. Sayısal Yöntemler ve Matlab Uygulamaları: İstanbul, Nobel Akademik Yayınc1lik, 384s.

Uzunboy, M., 2016. Chebyshev Türevleme Matrisleri ve Bazı Uygulamaları. Yüksek Lisans Tezi, Pamukkale Üniversitesi Fen Bilimleri Enstitüsü. Denizli, 57s.

Üstün, A., 2013. Jeodezide yaklaşım yöntemleri: Enterpolasyon ve Kollokasyon Lisansüstü Ders Notlar1, https://docplayer.biz.tr/84760425Jeodezide-yaklasim-yontemleri-enterpolasyonve kollokasyon.html. 8 Eylül 2020

Wright, K., 1964. Chebyshev Collocation Method for Ordinary Differantial Equations. The Computer Journal, 6(4), 358-365. 